\title{
Analysis on Existing Problems of Music Education Reform in the New Era
}

\author{
Wenmin Zhong \\ School of Music and Dance \\ Qujing Normal University \\ Qujing, Yunnan, China 655011
}

\begin{abstract}
After the establishment of the People's Republic of China (PRC) in 1949, the national leaders, Education Departments, and education experts studied the advanced educational system and ideology in western world, as well as deeply researched and discussed the then education status in China. Based on this, they have adjusted the outmoded educational pattern and content in our country and emphasized a comprehensive development of the educated in such aspects as moral, intelligence, sports, aesthetics and labor education. Up to now, great development and advancement in moral, intelligence and sports education have been achieved by continuous education reform. However, there is great deficiency in aesthetics education, which namely is such art course as music and painting. In this paper, the author analyzes the problems in music education.
\end{abstract}

Keywords—music education; musical accomplishment; music education resources

\section{THE SIGNIFICANCE OF MUSIC EDUCATION}

The sentence "There are three keys to open the treasure house of human wisdom, which are respectively math, literature and note." written by Victor Hugo speaks for the importance of music. Music can decipher human intelligence and advance human development. Therefore, music education is a privilege of everybody but not of the few. Moreover, music education should not specifically cultivate professional musician but be a required course to all students. By this universal music education, the educated would improve their ability in discovering and appreciating beauty, and cultivate his creativeness, which leads them to develop comprehensively and thus to build and level up socialist spiritual and Chinese civilization.

From ancient times, Music education has been paid high attention both at home and abroad. The sentence "Nothing is more effective than music in changing social ethos and customs." in Classic of Filial Piety indicates that the best way to change into better folk custom is to use educated music, which illustrates the enormous function of music. The ancient Greek philosopher Plato said, "In education, we always use sports to the body, the soul to music." To build up body, one needs to do exercise. Likewise, to refresh mind and to form noble morality and sentiment, one needs to listen beautiful and pleasant music. Plato's viewpoint on music shares a feature of the ancient Chinese thoughts. Modern medicine has proved that the right cerebral he misphere controls human creativeness, and music acts directly on and thus develop the right brain. Hence one can see that music is of great significance in developing intelligence. The great scientist Albert Einstein once said, "Many of my scientific achievements are inspired by music." Music education to develop the right brain of the educated can be regarded as one of the good methods in creative and practical improvement. "Music is a powerful source of thought." This is the world famous educator Sukhomlinskii's description about the greatness of music. All times and in all, people recognize the significance of music. Popularizing music education can not only cultivate noble sentiment and aesthetic appreciation but be a key means of progressing national quality and spiritual civilization.

\section{THE PRESENT SITUATION OF MUSIC EDUCATION IN CHINA}

China has a huge music education system, which includes about Two hundred thousand music teachers, more than two hundred million music students and 388 higher music education institutions to train music teachers. These groups and institutions shoulder the responsibility of teaching music and inheriting national music culture. However, due to the current state, social environment, education system and ideology in China, the current music education system is still weak and imperfect, and people's overall music quality is not high.

As a vital part of quality-oriented education, music education undertakes an arduous task of fostering aesthetic ability. Hence greater importance should be attached to it. But music education reform and development of most regions in China cannot keep pace with quality education for economic and environmental and cultural ele ments.

\section{A. Difference in Music Education of East and West China}

Economically and intellectually open than West China, Eastern China has taken steps from test-oriented education to quality-oriented education in education mode. Such art education as music has been increasingly emphasized. In east China, music education shows a booming trend and its level is improved significantly.

However, the economy in west China lags behind and so does quality-education thought. Focusing on the traditional 
test-oriented education, the education mode in west China lays particular stress on cultural knowledge but not on overall quality. In some remote backward areas, the aim of education is high scores. Whether the students are tone-deaf or not is without the scope of education. More badly, due to the economic and resource limit in some poverty-stricken areas, the music education cannot be practiced though the importance is realized. Some regions of west China have a developed economy and a comparatively high level in overall-quality education. But these regions cannot represent the general educational level.

\section{B. Difference in Music Education of Urban and Rural Areas}

The great difference in the economic development degree and the thoughts shaped by binary structure of urban and rural areas makes the quality education in rural areas lag behind that in urban areas. In the countryside, music education is done in school because of the economic limits. Hence, the school's level of music education directly influences that of the educated. Furthermore, the educational environment and equipment in the countryside is far behind that in the cities. The incomplete teaching equipment would have bad impact on the achievement of the teaching goal, as well as the quality and effect of the music education, which is a long-lasting problem in smoothly promoting music education.

On the contrary, due to the good economic environment and advanced educational ideas in urban areas, music education can be done by both school and businesslike approach which is funded by family and offered by the market. Moreover, the environment and equipment of music education in cities are beyond the reach of that in the countryside.

\section{THE CURRENT EXIST ING PROBLEMS ON MUSIC EDUCATION IN CHINA}

According to the current situation of music education in west or east and rural or urban areas, there exist some problems, due to such factors as national conditions, economy, social environment and humanist values, mainly manifested in the following points:

\section{A. The Poor Music Teacher Force}

The arrangement of music teachers is a major obstacle in the developing course of music education no matter in the countryside or cities. Roughly, the number of the existing rural elementary and middle schools in China is nine hundred thousand whereas that of the music teachers is only ten thousand, which means averagely every nine schools equipped with one music teacher.

What's more, owing to the shortage in professional music teachers, some schools would arrange the non-professional music teachers to teach the music courses. Shifted into music teaching from other disciplines, these teachers are unqualified for their lacking in formal and professional music training as well as in music quality and teaching notion.

\section{B. The Lacking Music Teaching Equipments}

The Music Curriculum Standard in Full-time Compulsory Education said explicitly, "Besides the teachers' manual in text, the use of multimedia assisted teaching software is strongly advocated. Audiovisual teaching material should match up to the selected songs in textbook and present itself in various forms (audio and video tapes, VCD)." As an important tool in music teaching, the teaching equipment based the improvement of music teaching method and quality. Nonetheless, schools in many regions have a serious shortage of equipment even not owning one decent instrument. Even worse, schools in some regions do not have the classroom for music teaching, not saying to the basic music equipment. As for professional music classroom, piano, multimedia devices, and so on, it is only a dream of music teachers and students . No matter how professional a music teacher is, it is unapproachable to achieve the expected result and to cultivate students' music quality. Therefore, the lacking music teaching equipment urgently needs to be solved by the education department.

\section{The Outdated Music Teaching Materials}

The present music teaching materials in China are not pertinent to the education conditions in the poor regions and claim for high knowledge and skills. Thus the music teachers are not qualified while the students are difficult to understand, which leads to the unsatisfying teaching results. Not relating to the dedicatee's living and growing experience, the content of the textbooks cannot resonate for and interest them. For instance, difficult to sing, some songs cannot be accepted by students; the young people are prone to the popular songs but the course selects traditional songs and does not introduce the popular ones. All the above reasons leads to an unscientific teaching easy to be disconnect with reality and the failure of the expected music quality though students love attend the music class.

\section{The Lagging Music Teaching Method}

Traditional collective teaching form is still adopted in the present music teaching mode. This kind of teaching mode cannot teach in accordance of students' aptitude. On the other hand, it cannot fully arouse students' learning enthusiasm for music, which make the music course a mere formality. As active as the class atmosphere and students, the music teaching goal namely enhancing the ability of cultural cultivation, appreciation, aesthetic taste and comprehensive quality is not achieved for teacher's lagging music teaching method and low teaching level. In addition, the method mode, and theoretical research and discussion of music education is insufficient in China, which brings about teachers that do not master the theory and ability of music teaching. It is another reason why music teaching cannot achieve the goal.

\section{E. The Neglected Music Education}

A phenomenon highlighting enrolment rate but neglecting music education is regarded as a normal for a long time in China. Suffering from the pressures of high enrolment rate, elite school titles and parents' dream of their children's bright future, school leaders have to improve students' test scores by 
all means, which results in a phenomenon marked by actually aiming to test-oriented education and seemingly qualityoriented education. Pursuing for the only goal - enrolment rate, school leaders also take score rank as the exclusive standard for evaluating school's quality and teachers' performance. Therefore, this standard generates the following results: the comprehensive quality of the educated and the music teachers is neglected; the time for music learning is occupied by English or Math and becomes a sacrifice for tests; under the pressure given by parents and teachers, the educated themselves do not have the time and energy to self educate the quality courses such as music.

\section{PROPOSALS FOR MUSIC EDUCATION REFORM}

On account of the above problems in present music education, people need reflect and the department need lay more emphasis and nurturing for the purpose of changing the situation of music education and then advancing it.

\section{A. To Shift the Thoughts and to Enhance the Status of Music Education}

A large part of aesthetic ability in quality-oriented education is cultivated by music education. Music education intends to develop a healthy aesthetic sentiment and improve the aesthetic ability. As an essential way to imple ment qualityoriented education, music education can not only rich the emotional world and promote the soul but also shape a sound personality and cultivate imagination and creativity, which contributes to the self all-round development.

\section{B. To Raise the Professional Level of Music Teachers and Their Teaching}

The shortage of music teacher force is one important reason for the low level of the music education in China especially in the far-away backward areas. To address this shortage, the author holds that better environment and equipment of music education should be created for music teachers. Moreover, the author also thinks that by expanding enrolment, specially selecting, specialized music training and so on, the government should do more efforts in the cultivation of outstanding music teachers to meet demand.

\section{To Strengthen the Necessary Investment in Music Education}

The necessary equipment of education makes great difference on teaching results. It is especially true when it comes to the music education. Without professional music teaching facilities, it is hard to obtain good effects no matter how outstanding the music teacher is. In most remote areas especially in rural mountain villages, both the poor economy and limited fiscal revenue invested into more important fields conduce to the shortage of music facilities. Teachers have to teach music in the simplest ways, which cannot satisfy the needs of music education reform at all, let alone the qualityoriented education.

\section{To Construct a Scientific System of Music Education}

In order to construct a scientific system of music education, the author makes some suggestions in the following lines. First of all, because the music teaching materials play a vital role in the results of music education, the content and design of the materials should keep pace with the times and highlight its features for the purpose of increasing students' interest. What's more, a scientific music teaching system should be gradually constructed to address such problem as narrow course cover and occupying phenomenon. Lastly, by establishing a thorough music teaching system, summarizing a scientific and reasonable music teaching methods, as well as building a better curricular system centering on the core courses in music education, then comprehensive understanding and appreciation of music are received by the educated, which fully heightens the effects of music education.

\section{CONCLUSION}

Music education, as a key process in quality-oriented education, is of great importance for the educated, education system and China's long-term development. The reform and development of music education in the new era put forward corres ponding requirements in teacher force, education system, education mode, fiscal funds and social thoughts. There are chances as well as challenges in music education. It is must to define its importance and improve its status. Only by analyzing its problems, as well as proposing, earnestly working on and actively exploring the practical countermeasures can the music education in China have further breakthrough and development.

\section{REFERENCES}

[1] Liu Peizhu. Practical and Theoretical Research on Music Education [M]. Shanghai Music Publishing House, 2004

[2] Zeng Suijin. Social Function of Music and Chinese Advanced Culture [J]. Chinese Culture News, 2001, (08), 18

[3] He Yang. On the Observation and Thinking of American Music Education [J]. World Music, 2009(8)

[4] Niu Xueyao. Discussion on Some Problems of Music education in Primary and Secondary Schools in Rural Areas of China [J]. Elementary School Science (Teacher Forum), 2011, (02): 48

[5] Li Jun. "Disease" and "Treatment" of Music Education in Primary and secondary Schools in Rural Areas [J]. Music Education in Primary and Secondary Schools, 2008, (12): 9-10

[6] Sun Weimin. Problems and Countermeasures of Music Education in Primary and Secondary Schools in Rural Areas [J]. New Curriculum (Teacher Edition), 2006, (08), 28

[7] Wang Huan. On the Current Situation and Thinking of High School Music Education [J]. New curriculum (Middle School), 2012, (07): 48 